\title{
ГЕНЕЗИС ПОНЯТИЯ БИОПОЛИТИКИ: ОТ СОЦИОБИОЛОГИЗМА К ПОСТСТРУКТУРАЛИЗМУ
}

\begin{abstract}
Аннотация. Объект статьи - биополитика. Предметом данного научного исследования является понятие биополитики, его генезис и эволюция. В статье подробно исследуется происхождение данного термина, его эволюция и границы современного употребления в рамках западной политической науки. Особо отмечается изменение применения данного термина. Выделяется роль М. Фуко как новатора, который дал новое понимание проблеме биополитического измерения социальной реальности. Подчеркивается роль Дж. Агамбена, Н. Роуза как продолжателей фукольдианской традиции интерпретации понятия биополитики. Методом исследования в данной статье является анализ смысла понятия “биополитика" в трактовках различных авторов. Используется текстологический анализ, который позволяет выявить различия в интерпретации данного понятия у разных исследователей. Основными выводами произведенного исследования являются: 1)построение периодизации развития понятия биополитика, основанного на трансформации смысла, закладываемого различными авторами; 2) Выявлении внутреннего содержания понятия биополитики, которое использовалось различными представителями политической науки. Делается вывод о революционности новаций М. Фуко, который привнес новое толкование данного термина, значительно расширив его понимания и переосмыслив природу властных взаимодействий в эпоху зрелого модерна.
\end{abstract}

Ключевые слова: биополитика, постструктурализм, либерализм, постмодернизм, история понятия, биовласть, Фуко Мишель, Роуз Николас, генеалогия, социобиологизм.

\begin{abstract}
This article reveals the evolutionary process of forming patterns of development and political decision-making in the Russian Federation on the national government level. The author notes that during Russia's recent history (from the time of formation of the Russian Federation in 1991) the country has sequentially changed three models of development and execution of decisions: polycentric, vertically centralized, and mixed (currently in force). The methodological basis of the study is a systematic, structural and functional, comparative political approach, methods of analysis, synthesis, induction, deduction, observation.Each of the above patterns of development and political decision-making (polycentric, vertically centralized and combined) corresponds to the socio-political formation of the Russian state at certain stages of its development, and gave way to the next model under the influence of radical changes in the political life of Russian society, which brought substantial changes in the political system and the political regime in Russia. Together, all three models are stages of the same evolutionary process, extrapolation of which allows forecasting the changes to the Russian Federation's combined model of development and political decision-making in the future..
\end{abstract}

Keywords: Political system, Russia, World politics, Synergetic vision, International relations, Diplomacy, Interests, State, Security, Risks.

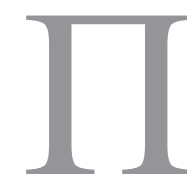
онятие биополитики одно из самых сложных и не конвенциональных понятий в политической науке. Оно проделало путь от развития в рамках различных социобиологических теориий, где обозначало совокупность техник контроля численности населения, до существования в рамках постструктуралистских концепций, где описывало новые формы формирования индивида властью. В отечественной политической науке практически отсутствуют существенные исследования, посвященные генезису понятия биополитики в рамках западной политической науки. Однако можно отметить существенный рост интереса к самому понятию в последние годы.

Понятие биополитики становится предметом оживленной дискуссии ввиду отсутствия конвенционально установленного определения или подхода к данному явлению. По мнению ряда исследователей[12, p.158], понятие биополитики впервые появляется в рамках учения Рудольфа 


\section{Тренды и управление 1(13) • 2016}

Челлена, определявшего биополитику как совокупность политических решений и действий, которые направлены на формирование «жизни общества: духа, души, системы». Рассматривая биополитику как элемент оригинальной органицистской теории [11, p.16], он пришелк заключению, что ключевую роль в ней играло государство, определяемое им как коллективная сверхличностная организация [12, р.11], которая обеспечивает воспроизводство населения, поддерживает его жизнедеятельность и формирует политику в области здравоохранения.

Впоследствии, в рамках расовых теорий биополитика стала увязываться с евгеникой и расовыми законами. Ханс Райтер - глава Общества кайзера Вильгельма, использовал термин биополитика для описания программы увеличения немецкого населения и улучшения их генетического материала[16, р. 37-43]. Рассматривая биополитику как совокупность усилий государства и нации для улучшения «арийской породы», Х. Райтер видел необходимость в ограничении рождаемости «низших» рас, инвалидов, психически больных людей и создании условий максимального благоприятствования для увеличения численности «арийцев».

В предвоенные годы на североамериканском континенте также актуализировалась проблематика биополитики. В 1938 году М. Робертсом была написана книга «Биополитика». В ней обсуждалась взаимосвязь между биологическими феноменами и политическим поведением. В 1964 году Линтон Колдвелл выявил влияние биологических феноменов на политическое участие[9, p. 1-16]. Он пытался объяснить зависимость между окружающей средой и физиологией человека, с одной стороны, и политическим процессом - с другой. Группа американских ученых, принявших подобное толкование биополитики, организовали Ассоциацию политических исследований и наук о жизни (Association for Politics and the Life Sciences), (APLS).

В 70-е годы XX века Мишель Фуко переосмыслил представления о биополитике[12, с.6] как о сциентистском термине и предложил свою оригинальную теорию. Новое определение биополитики, предложенное М. Фуко, вскоре стало доминировать в политико-философском дискурсе на европейском континенте. Изучение проблемы новых технологий власти, стало отправной точкой для множества иных исследований[8, с.257]. М. Фуко утверждал, что биополитика - «совокупность процессов, включающих в себя пропорцию рождений и смертей, уровень воспроизводства, рост населения» [8, с.257]. Новое содержание, которое заложил М. Фуко в основание концепции биополитики, позволило уйти от ограниченности социобиологизма. Он регистрирует первые элементы использования биополитики в рамках европейской цивилизации еще в конце XVIII века. В рамках биополитического диспозитива происходит окончательное и полное подчинение индивида. В конце XVIII века происходит зарождение биополитического диспозитива как механизма управления группами индивидов. Данная форма контроля преобразует общество при помощи медицины, экономических институтов и новых форм «правительствености» (governmentality). Биополитика утверждает свою власть посредством: а) гигиенической системы; б) контроля над рождаемостью и смертностью; в) заботой о недееспособных, инвалидах и создании системы социальной защиты; г) охраны окружающей среды, осушением болот и контролем над эпидемиологической обстановкой на европейском континенте.

Финальным элементом, позволившим закрепить подобные технологии власти, стала проблема нового типа среды, созданного в рамках жизнедеятельности человека[12, с.258]. Вся эта совокупность проблем получила свое разрешение (или же была попытка решить их) в рамках биополитики с XIX по XXI век.

В 1978-1979 годах М.Фуко читает курс «Рождение биополитики». В рамках данного курса он обращается к проблематике понимания либерализма. Этот курс является органическим продолжением курса «Безопасность, территория, население», в котором формулируется проблема генезиса политического знания, сосредоточенного на понятии населения и механизмах, способных обеспечить его регулирование[12, с.469]. Оба эти курса объединены интересом к проблеме «власти над жизнью»[12, с.477].

Концепция М. Фуко переосмысливалась как в рамках философских школ на европейском континенте, так и в рамках политической науки в США. Взгляд М. Фуко на биополитический 


\section{Теория и методология управления}

аспект власти смог окончательно утвердиться только в 2004 году, когда на ежегодном собрании Американской ассоциации политических наук в Чикаго большая часть присутствующих политических ученых согласилась с подобной постструктуралистской трактовкой данного термина [12, p 2]. На данный момент можно с уверенностью утверждать, что концепция М. Фуко заняла доминирующее положение в рамках биополитических исследований.

Новые вызовы, которые стоят перед политической наукой, создаются проникновением государства и иных институциональных образований в сферу управления телом, актуализируют проблему биополитики не только как теоретическое умозрительное построение, но и как факт актуальной политической повестки. Биометрический паспорт, надсмотр и контроль над телесностью, создаваемый в современных западных обществах, поставил ребром проблему защиты индивида и актуализировал понятие «биополитики».

Необходимо обозначить методологические основания, которыми руководствовался М. Фуко. Проблема разработки новой методологии, позволившая ему проникнуть за границы привычного объекта исследования, была ключевой в 60-е годы XX века и все еще оставалась значимой в 70-е годы XX века.

Современные левые итальянские философы Антонио Негри [6, с.440], Роберто Эспозито [10, p.225] и Джорджио Агамбена [1, с.29-46] продолжают разрабатывать постмодернистскую версию понимания биополитики. Они уходят от фукольдианского понимания биополитики как качественно нового типа властвования, удерживающего телесность как основной объект поля их деятельности.

Уже во второй декаде XXI века происходит реактуализация интереса к данной проблеме. В 2013 году Соденторнский университет выпустил сборник работ разных авторов под общим названием «Биополитика и Правительственность». В них были опубликованы статьи таких авторов, как Томас Лемпке [13, р.172], Маурицио Лаццарато [15, р.135 - 153], Свен-Олав Валленштайн [21, р.7-34], Катрина Миллс [15, р.73-90], Джулиан Рейд [17, р.91-104], Лукас Станек [19, р.105-124] и другие. В данном сборнике попытались систематизировать исследования различных авторов, направленных на изучение биополитики. Стоит особое внимание уделить Николасу Роузу [18, р.439-463], который был вдохновлен идеями М. Фуко, в рамках которых разрабатывает проблематику устройства нового неолиберального порядка. Он солидаризируется с М. Фуко в проблеме обнаружения биополитического диспозитива. Вслед за М. Фуко он утверждает, что либерализм есть наиболее полное проявление биополитических техник властвования. Базовой установкой Роуза является утверждение, что либерализм как совокупность управляющих техник выстраивалась в противовес raison d'Йtat и всеобщего дисциплинарного общества. Действительно, модель raison d'Йtat, как показал М. Фуко, стремилась к всеобщему правлению населением исходя из рационализированной логики, согласно которой сила государства коррелирует с территорией, населением и богатством. Дисциплинарные техники стремятся к всеобщей прозрачности, проверяемости и обнаружимости. Либерализм как совокупность техник, по мысли Н. Роуза, отказывается от избыточности этих подходов. Он нивелирует избыточное присутствие и силы, затрачиваемые на контроль над индивидами. Подобную либеральную систему он называет «развитым либерализмом» [5, с.192-216].

В заключение, необходимо выделить периодизацию генезиса и развития биополитического концепта в рамках западной политической науки:

1. Социобиологический (начало XX века - 60 годы ХХ века)

2. Фукольдианский (70-е - 80-е года XX века)

3. Постфукольдианский (90-е года XX века - начало XXI века)

На первом этапе различные мыслители стремились увязать биологические функции человека и тип его политического активизма. На данном этапе далось предположение, что при изменении политики в области здравоохранения возможно минимизировать риск политической нестабильности и улучшить производительность на селения.

М. Фуко произвел революцию в подобном ставшим уже классическим пониманием биопо- 


\section{Тренды и управление 1(13) • 2016}

литики, рассматривая человека как социальный конструкт, стремясь показать, что новый тип системы власти, появившийся на рубеже XVIIIXIX веков, призван реконструировать человеческую субъективность, завершив переход к новому типу отношений власти и отдельного индивида, где власть не только угрожает смертью, но и контролирует жизнь.

Наследники М. Фуко, в целом соглашаясь с его взглядом на данный тип практик, скорее пытались выявить общие элементы, характерные для любого периода истории, обозначая их как биополитические. Уходя от фукольдианской трактовки биополитики как нового типа власти, они утвердили понимание биополитики как основного типа властвования на протяжении всей истории. С другой стороны, многие политические исследователи заимствовали критические замечания М. Фуко относительно конституирования неолиберального режима.

\section{Библиография}

1. Агамбен Дж. Ното sacer. Что остается после Освенцима. Архив и свидетель. Перевод с итальянского: Ольга Дубицкая, И. Левина, П. Соколов. Европа 2012. 192 с.

2. Агамбен Дж. Открытость. Человек и животное / Пер. с итал. Д. Новикова // Синий диван. - 2007. — №10-11. - С. 29-46

3. Ден В. Учение Рудольфа Челлена [Электронный ресурc]. URL: http://ecgeo.spbu.ru/doc/ Den\%20vs\%20Rudolf_Kjellen.pdf (дата обращения: 23.08.2015)

4. Лаццардо М. Биополитика/Биоэкономика [Электронный ресурс]. URL: http://multitudes.samizdat. net/IMG/pdf/Revue_des_revues-LAZZARATO-trad-russe.pdf (дата обращения: 20.04.2013)

5. Роуз Н. Управление «развитыми» либеральными демократиями / Логос №6, 2008 // Издательство Института Гайдара С. 192-216

6. Негри А., Хардт М. Империя / Пер. с англ. , под ред. Г. В. Каменской, М. С. Фетисова. - М.: Праксис, $2004-440 \mathrm{c}$.

7. Фуко М. Безопасность, территория, население. Курс лекций, прочитанных в Коллеж де Франс в 1977-1978 учебном году // СПб.: Наука, М. 2011. 544 с.

8. Фуко М. Нужно защищать общество: Курс лекций, прочитанных в Коллежде Франс в 1975-1976 уч. г. СПб.: Наука, 2005312 с.

9. Caldwell L, "Biopolitics: Science, Ethics, and Public Policy," The Yale Review, 1964: 54 (1) p. 1-16

10. Esposito R. Bios. Biopolitica e filosofia", Einaudi, 2004; Trans. Timothy Campbell as "Bmos: Biopolitics and Philosophy", Minnesota University Press, 2008. p. 225

11. Lazzarato M. Enunciation and Politics// Foucault, Biopolitics, and Governmentality Edited by Jakob Nilsson \& Sven-Olov Wallenstein Sцdertцrn University The Library (C) The authors Graphic Form: Jonathan Robson \& Per Lindblom Printed by E-print, Stockholm 2013 p. 135 - 153

12. Laurette T., Walsh M. Elmhurst College, Elmhurst, IL The Competing Meanings of "Biopolitics" in Political Science: Biological and Post-modern Approaches to Politics. To be presented at the American Political Science Association's Annual Meeting, Seattle, WA, September 1, 2011. p. 1-30

13. Lemke T. Biopolitics: An Advanced Introduction/ NYU Press. 2011 // Lemke T. Perspectives on Genetic Discrimination/ Routledge Advances in Sociology (Book 100) 172 p.

14. Lemke T. Foucault, Politics and Failure// Foucault, Biopolitics, and Governmentality Edited by Jakob Nilsson \& Sven-Olov Wallenstein Sцdertцrn University The Library @ The authors Graphic Form: Jonathan Robson \& Per Lindblom Printed by E-print, Stockholm 2013 p. 35-53

15. Mills C. Biopolitical Life // Foucault, Biopolitics, and Governmentality Edited by Jakob Nilsson \& SvenOlov Wallenstein Sцdertцrn University The Library (c) The authors Graphic Form: Jonathan Robson \& Per Lindblom Printed by E-print, Stockholm 2013 p. 73-90 
16. Reiter H, "Unsere Biopolitik und das Auslandsdeutschtum," in Das Reichsgesundheitsamt 1933-1939. Sechs Jahre nationalsozialistische Fuhrung (Berlin: Julius Springer Verlag, 1939) pp. 37-43. Cited in Lemke 2010

17. Reid J. Towards an Affirmative Biopolitics Life // Foucault, Biopolitics, and Governmentality Edited by Jakob Nilsson \& Sven-Olov Wallenstein Sцdertцrn University The Library @ Jonathan Robson \& Per Lindblom Printed by E-print, Stockholm 2013 p. 91-104

18. Rose N. 'Society, madness, and control', in A. Buchanan, ed., The Care of the Mentally Disordered Offender in the Community, pp. 3-25, Oxford: Oxford University Press// Biological Citizenship', in Aihwa Ong and Stephen Collier, eds., Global Assemblages: Technology, Politics and Ethics as Anthropological Problems, pp. 439-463. Oxford: Blackwell, 2005

19. Stanek L. Biopolitics of Scale// // Foucault, Biopolitics, and Governmentality Edited by Jakob Nilsson \& Sven-Olov Wallenstein Sцdertцrn University The Library (C) The authors Graphic Form: Jonathan Robson \& Per Lindblom Printed by E-print, Stockholm 2013 p.105-124

20. Walenstein S-O Introduction: Foucault, Biopolitics, and Governmentality// Foucault, Biopolitics, and Governmentality Edited by Jakob Nilsson \& Sven-Olov Wallenstein Sцdertцrn University The Library (C) The authors Graphic Form: Jonathan Robson \& Per Lindblom Printed by E-print, Stockholm 2013 p. 7-34

\section{References (transliterated)}

1. Agamben Dzh. Homo sacer. Chto ostaetsya posle Osventsima. Arkhiv i svidetel'. Perevod s ital'yanskogo: Ol'ga Dubitskaya, I. Levina, P. Sokolov. Evropa 2012. 192 s.

2. Agamben Dzh. Otkrytost'. Chelovek i zhivotnoe / Per. s ital. D. Novikova // Sinii divan. — 2007. — №1011. - C. 29-46

3. DenV.Uchenie Rudol'fa Chellena[Elektronnyiresurs].URL:http://ecgeo.spbu.ru/doc/Den\%20vs\%20Rudolf_ Kjellen.pdf (data obrashcheniya: 23.08.2015)

4. Latstsardo M. Biopolitika/Bioekonomika [Elektronnyi resurs]. URL: http://multitudes.samizdat.net/ IMG/pdf/Revue_des_revues-LAZZARATO-trad-russe.pdf (data obrashcheniya: 20.04.2013)

5. Rouz N. Upravlenie «razvitymi» liberal'nymi demokratiyami / Logos №6, 2008 // Izdatel’stvo Instituta Gaidara S. 192-216

6. Negri A., Khardt M. Imperiya / Per. s angl., pod red. G. V. Kamenskoi, M. S. Fetisova. — M.: Praksis, 2004 $-440 \mathrm{~s}$.

7. Fuko M. Bezopasnost', territoriya, naselenie. Kurs lektsii, prochitannykh v Kollezh de Frans v 1977-1978 uchebnom godu // SPb.: Nauka, M. 2011.544 s.

8. Fuko M. Nuzhno zashchishchat' obshchestvo: Kurs lektsii, prochitannykh v Kollezh de Frans v 1975-1976 uch.g. SPb.: Nauka, 2005312 s.

9. Caldwell L, "Biopolitics: Science, Ethics, and Public Policy," The Yale Review, 1964: 54 (1) p. 1-16

10. Esposito R. Bios. Biopolitica e filosofia", Einaudi, 2004; Trans. Timothy Campbell as "Bmos: Biopolitics and Philosophy", Minnesota University Press, 2008. p. 225

11. Lazzarato M. Enunciation and Politics// Foucault, Biopolitics, and Governmentality Edited by Jakob Nilsson \& Sven-Olov Wallenstein Sцdertцrn University The Library (C) The authors Graphic Form: Jonathan Robson \& Per Lindblom Printed by E-print, Stockholm 2013 p. 135 - 153

12. Laurette T., Walsh M. Elmhurst College, Elmhurst, IL The Competing Meanings of "Biopolitics" in Political Science: Biological and Post-modern Approaches to Politics. To be presented at the American Political Science Association's Annual Meeting, Seattle, WA, September 1, 2011. p. 1-30

13. Lemke T. Biopolitics: An Advanced Introduction/ NYU Press. 2011 // Lemke T. Perspectives on Genetic Discrimination/ Routledge Advances in Sociology (Book 100) 172 p. 


\section{Тренды и управление 1(13) • 2016}

14. Lemke T. Foucault, Politics and Failure// Foucault, Biopolitics, and Governmentality Edited by Jakob Nilsson \& Sven-Olov Wallenstein Sцdertцrn University The Library (c) The authors Graphic Form: Jonathan Robson \& Per Lindblom Printed by E-print, Stockholm 2013 p. 35-53

15. Mills S. Biopolitical Life // Foucault, Biopolitics, and Governmentality Edited by Jakob Nilsson \& SvenOlov Wallenstein Sцdertцrn University The Library (c) The authors Graphic Form: Jonathan Robson \& Per Lindblom Printed by E-print, Stockholm 2013 p. 73-90

16. Reiter H, "Unsere Biopolitik und das Auslandsdeutschtum," in Das Reichsgesundheitsamt 1933-1939. Sechs Jahre nationalsozialistische Fuhrung (Berlin: Julius Springer Verlag, 1939) pp. 37-43. Cited in Lemke 2010

17. Reid J. Towards an Affirmative Biopolitics Life // Foucault, Biopolitics, and Governmentality Edited by Jakob Nilsson \& Sven-Olov Wallenstein Sцdertцrn University The Library (C) The authors Graphic Form: Jonathan Robson \& Per Lindblom Printed by E-print, Stockholm 2013 p. 91-104

18. Rose N. 'Society, madness, and control', in A. Buchanan, ed., The Care of the Mentally Disordered Offender in the Community, pp. 3-25, Oxford: Oxford University Press// Biological Citizenship', in Aihwa Ong and Stephen Collier, eds., Global Assemblages: Technology, Politics and Ethics as Anthropological Problems, pp. 439-463. Oxford: Blackwell, 2005

19. Stanek L. Biopolitics of Scale// // Foucault, Biopolitics, and Governmentality Edited by Jakob Nilsson \& Sven-Olov Wallenstein Sцdertцrn University The Library @ The authors Graphic Form: Jonathan Robson \& Per Lindblom Printed by E-print, Stockholm 2013 p.105-124

20. Walenstein S-O Introduction: Foucault, Biopolitics, and Governmentality// Foucault, Biopolitics, and Governmentality Edited by Jakob Nilsson \& Sven-Olov Wallenstein Sцdertцrn University The Library (C) The authors Graphic Form: Jonathan Robson \& Per Lindblom Printed by E-print, Stockholm 2013 p. 7-34 